\title{
Structural Reliability Estimation with Vibration-Based Identified Parameters
}

\author{
Serdar Soyoz, M.ASCE${ }^{1}$; Maria Q. Feng, M.ASCE ${ }^{2}$; and Masanobu Shinozuka, Hon.M.ASCE ${ }^{3}$
}

\begin{abstract}
This paper presents a unique structural reliability estimation method incorporating structural parameter identification results based on the seismic response measurement. In the shaking table test, a three-bent concrete bridge model was shaken to different damage levels by a sequence of earthquake motions with increasing intensities. Structural parameters, stiffness and damping values of the bridge were identified under damaging seismic events based on the seismic response measurement. A methodology was developed to understand the importance of structural parameter identification in the reliability estimation. Along this line, a set of structural parameters were generated based on the Monte Carlo simulation. Each of them was assigned to the base bridge model. Then, every bridge model was analyzed using nonlinear time history analyses to obtain damage level at the specific locations. Last, reliability estimation was performed for bridges modeled with two sets of structural parameters. The first one was obtained by the nonlinear time history analysis with the Monte Carlo simulated parameters which is called nonupdated structural parameters. The second one was obtained by updating the first set in Bayesian sense based on the vibration-based identification results which is called updated structural parameters. In the scope of this paper, it was shown that residual reliability of the system estimated using the updated structural parameters is lower than the one estimated using the nonupdated structural parameters.
\end{abstract}

DOI: 10.1061/(ASCE)EM.1943-7889.0000066

CE Database subject headings: Shake table tests; Vibration; Identification; Structural reliability; Parameters; Bayesian analysis; Monte Carlo method; Kalman filters.

Author keywords: Shaking table test; Vibration-based; Identification; Reliability; Bayesian; Monte Carlo; Extended Kalman filter.

\section{Introduction}

Estimation of structural reliability has been the ultimate goal of the structural health monitoring practice (Doebling et al. 1996), but so far little research has been done on this topic. Some of the available efforts along this line can be summarized as follows: Park et al. (1985) introduced damage index for the reinforced columns and correlate this to the real-world structural damageability. Beck and Katafygiotis (1998) and Katafygiotis and Beck (1998) developed a methodology to update structural model and their uncertainties based on the measured data in Bayesian framework. Singhal and Kiremidjian (1998) used the Park-Ang damage index and Bayesian updating method to incorporate the 1994 Northridge Earthquake structural damage inventory into fragility analysis. Shinozuka et al. (2000b) developed empirical fragility curves for the bridge structures using Northridge Earthquake and 1995 Kobe Earthquake using nonlinear dynamic analysis. They compared the fragility functions obtained by nonlinear dynamic and static analysis in Shinozuka et al. (2000a). In addition, they

${ }^{1}$ Postdoc Researcher, Dept. of Civil and Environmental Engineering, Univ. of California, Irvine, Irvine, CA 92697. E-mail: ssoyoz@uci.edu

${ }^{2}$ Professor, Dept. of Civil and Environmental Engineering, Univ. of California, Irvine, Irvine, CA 92697. E-mail: mfeng@uci.edu

${ }^{3}$ Professor, Dept. of Civil and Environmental Engineering, Univ. of California, Irvine, Irvine, CA 92697. E-mail: shino@uci.edu

Note. This manuscript was submitted on March 26, 2008; approved on June 15, 2009; published online on June 22, 2009. Discussion period open until June 1, 2010; separate discussions must be submitted for individual papers. This paper is part of the Journal of Engineering Mechanics, Vol. 136, No. 1, January 1, 2010. CASCE, ISSN 0733-9399/2010/1$100-106 / \$ 25.00$. calibrated and verified their fragility model integrating information obtained from empirical, experimental, and numerical simulation (Shinozuka et al. 2003).

To obtain residual structural reliability after a damaging event, one uses a deterministic structure with known structural parameter values to analyze structural responses to different input motions. Therefore, the randomness in the response is due to the randomness in the input motion. In this study only one input motion was used for a specific level of shaking; however randomness in the response was due to randomness in the structural parameters. Prevailing thought has been that the randomness coming from structural strength is much smaller compared to the randomness in the ground motion variation. Usually the effect of randomness associated with structures is expressed in a structural strength variation factor (e.g., Banerjee and Shinozuka 2008).

In this study, the following steps were followed to determine the residual structural reliability after a damaging event. Monte Carlo simulation was performed to obtain a group of structural parameter. Each parameter was assigned to the base bridge model to generate a set of samples. Structural response was obtained using nonlinear time history analyses in terms of rotational ductility at the lower and the upper portions of each column for each bridge in the simulated set. Structural parameter identification results based on the seismic response measurements were used to update these results. As a result, two different distributions of response values in terms of ductility demand for each level of shaking were obtained: the first one from nonlinear time history analysis using Monte Carlo simulated structural parameters and the other one from Bayesian updated version of the first set based on the identification results. Afterwards, a threshold value was determined in terms of column rotational ductility. Failure prob- 


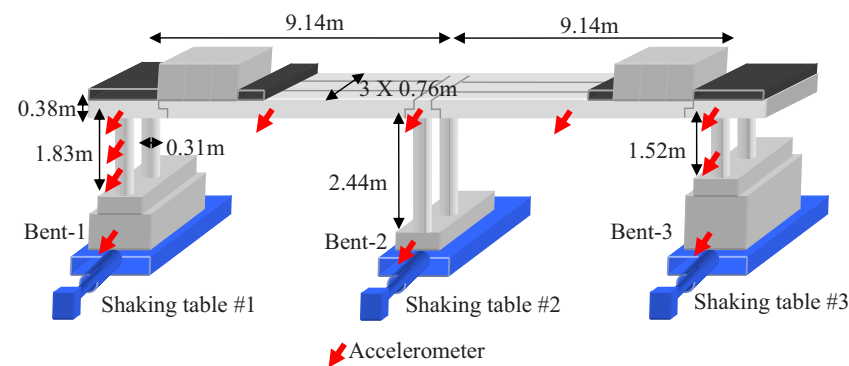

Fig. 1. Schematic view of the bridge model and sensor layout

ability, $P_{f}$, was defined as the probability that demand rotational ductility values exceed the threshold value under a given design earthquake. Residual structural reliability was evaluated using structural parameters either with or without Bayesian updated structural parameter values numerically simulated.

\section{Identification of Structural Parameters Based on Vibration Measurement}

This section presents the application of an extended Kalman filtering (EKF) approach developed previously by the writers (Soyoz and Feng 2008). It was applied for damage assessment by identifying change in structural parameters, stiffness, and damping values of the bridge structure under damaging seismic events based on the seismic response measurement. The seismic response accelerations analytically simulated using the identified stiffness and damping values agreed well with the measured accelerations, demonstrating the accuracy of the identified parameters.

\section{Proposed Damage Detection Method}

The EKF formulation, with details given in Grewal and Andrews (2001), can be summarized as follows, together with the proposed damage detection method. A second order equation of motion for a multi-degree-of-freedom system can be written

$$
M \cdot \ddot{u}(t)+C(t) \cdot \dot{u}(t)+K(t) \cdot u(t)=-M \cdot I \cdot \ddot{u}_{g}
$$

where $M=$ mass matrix; $C(t)=$ time varying damping matrix; $K(t)=$ time varying stiffness matrix; $u=$ relative displacement vector; $I=$ influence vector; and $\ddot{u}_{g}=$ input ground acceleration. $\ddot{u}+\ddot{u}_{g}$ and $\ddot{u}_{g}$ are measured, $M$ is calculated from the structural design drawings, and $C(t)$ is considered to be of Rayleigh type damping, i.e., linear combination of $K(t)$ and $M$ matrices. The

Table 1. Test Procedure

\begin{tabular}{llcc}
\hline Test & Ground motion description & $\begin{array}{c}\text { PGA } \\
(\mathrm{g})\end{array}$ & $\begin{array}{c}\text { Damage } \\
\text { description }\end{array}$ \\
\hline WN-1 & White noise in transverse & 0.07 & \\
T-13 & Low earthquake in transverse & 0.17 & Bent-1 yields \\
T-14 & Moderate earthquake in transverse & 0.32 & Bent-3 yields \\
WN-2 & White noise in transverse & 0.07 & \\
T-15 & High earthquake in transverse & 0.63 & Bent-2 yields \\
WN-3 & White noise in transverse & 0.07 & \\
T-19 & Extreme earthquake in transverse & 1.70 & Bent-3 steel buckles \\
WN-4 & White noise in transverse & 0.07 & \\
\hline
\end{tabular}
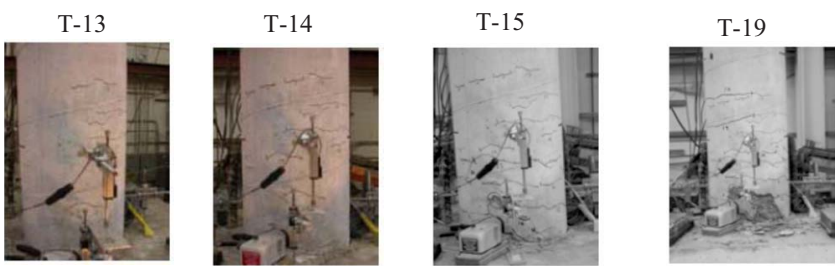

Fig. 2. Damage observed on Bent- 1 after each test

objective is to identify $K(t)$ which is directly used as the damage indicator.

An extended state vector is defined as

$$
x(t)=[u(t), \dot{u}(t), \Psi(t)]^{T}
$$

where $\Psi(t)=$ extended state. In this study, the extended states are the stiffness values for the lower and the upper portions of the columns.

State vector $x$ is obtained at each time step. As described in Eq. (2), the state vector contains information of not only displacement and velocity but also of the stiffness value. This means that the stiffness value is identified for each time step.

\section{Bridge Model and Test Procedure}

The shaking table experiment was conducted at the University of Nevada, Reno on the behalf of NEES projects (http:// nees.unr.edu). Fig. 1 shows the three-bent RC bridge model. Each of the bents has two columns. All the columns had the same design cross sections, but the bents were of different heights leading to different transverse stiffness. The shaking tables were driven by input acceleration in the transverse direction. Eleven FBA-11 (Kinemetrics Inc., Pasadena, Calif.) type accelerometers were used to obtain the vibration response of the bridge model in the transverse direction, with their locations indicated in Fig. 1.

Strong ground input motions were classified into different levels including low, moderate, high, severe, and extreme levels. Table 1 lists the sequence of the tests and the peak ground acceleration (PGA) of the inputs. The reason to introduce white noise excitation in between seismic excitations was to simulate traffic loading on the bridge after an earthquake. Three shaking tables were driven by the same signal to produce coherent input. Different levels of damage were observed on the bridge after each strong ground motion. The damage description shown in Table 1 represents the damage observed visually.

During the test, after each strong motion, cracks were marked and photos were taken to document the damage. Some examples were shown in Figs. 2 and 3. Due to different transverse stiffness of the bents, dynamic behavior was highly dominated by the tor-
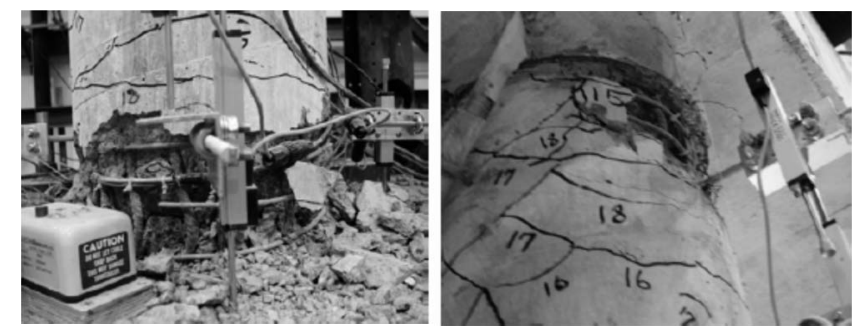

Fig. 3. Damage observed on the lower and upper portions of Bent-3 after T-19 
Table 2. Identified Stiffness Values

\begin{tabular}{llll}
\hline & T13 & T14 & T15 \\
\hline B1L & 0.78 & 0.48 & 0.21 \\
B2L & 0.92 & 0.89 & 0.61 \\
B3L & 0.80 & 0.64 & 0.30 \\
\hline
\end{tabular}

sion demanding high transverse movement for the first and the third bent. This explains the severe damage on these two and comparatively lighter damage on the second bent.

\section{Verification of Damage Detection Method}

Stiffness values in the damaged zones are considered as piecewise linear within each time step. However they are updated at each time step, so that the nonlinearity of the stiffness is taken into consideration. These identified stiffness values at each time step are referred to as instantaneous stiffness values. Table 2 shows the identified stiffness values at the lower portion of each column after seismic excitation T-13, T-14, and T-15. The stiffness values are presented by the ratio between the identified stiffness versus the original stiffness before damage. The stiffness values obtained after these three seismic excitations are used in the following sections of the paper.

Fig. 4 compares the time histories of the response acceleration at deck level to seismic excitation T-13 measured by the accelerometer and obtained by EKF. Fig. 4 shows an excellent agreement between the measured and simulated response accelerations. The excellent agreement confirms the accuracy of the identified instantaneous stiffness values during the event.

\section{Proposed Approach for Structural Reliability Estimation}

This section presents the proposed method for structural reliability estimation in more details. First, structural reliability estimation based on nonlinear time history analysis with the Monte Carlo simulated, nonupdated parameters were discussed. Then, the structural reliability estimation based on the Bayesian updated parameters was explained.

\section{Reliability Estimation Based on Nonupdated Structural Parameters}

Fig. 5 shows the flowchart to estimate the reliability using structural parameters generated by Monte Carlo simulation, without Bayesian updating of these parameters. First, stiffness values of the bridge were determined based on the structural design draw-

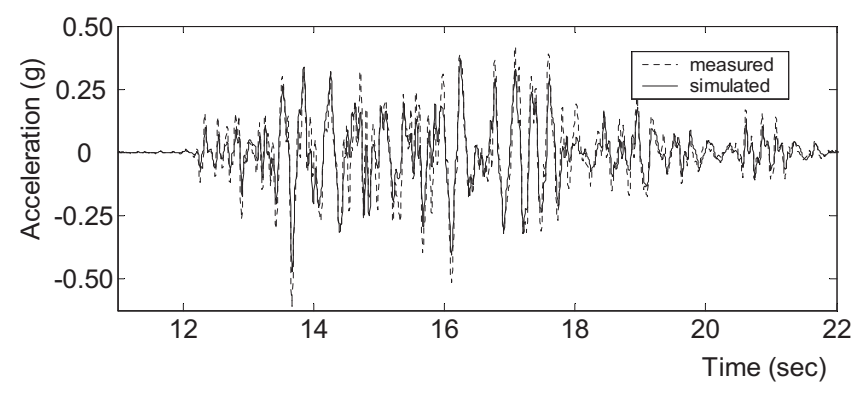

Fig. 4. Comparison of measured and identified accelerations

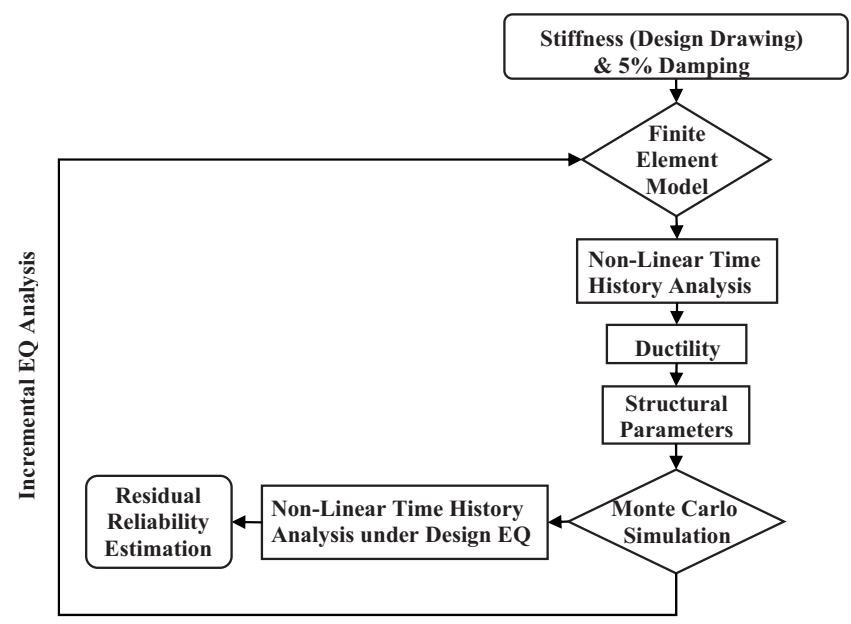

Fig. 5. Flowchart of the residual reliability estimation with nonupdated parameters

ings. Five percent modal damping values were assumed for the first and second modes and the corresponding Rayleigh damping coefficients were found. Eq. (3) shows how modal damping values can be related to Rayleigh damping coefficients

$$
\begin{gathered}
C=a K+b M \\
\xi_{i}=\frac{a}{2} w_{i}+\frac{b}{2} \frac{1}{w_{i}}
\end{gathered}
$$

where $C=$ damping coefficient; $K=$ stiffness; and $M=$ mass matrices. $a$ and $b$ are the two Rayleigh damping coefficients. $\xi_{i}$ is the damping ratio and $w_{i}$ is the frequency of the $i$ th mode.

Monte Carlo simulation was performed to generate 20 samples for the six stiffness values, at the lower and the upper portion of three bents and two Rayleigh damping coefficients. The samples were generated based on normal distribution. Coefficient of variation for the distributions was 0.1 .

Nonlinear time history analysis was performed in SAP2000.v8 using the first test, T-13 as the input motion. Nonlinearity was modeled as Wen type links, at both the upper and the lower parts of each column, one-half of the diameter of the column away from the end. The moment curvature relationship obtained using section properties (Johnson et al. 2006).

Rotational ductilities were obtained at six locations: lower and upper parts of the three bents (plastic hinge regions) based on the response values. Next, the relation between the identified stiffness values, which is discussed in the previous sections and the ductility values is presented. The identified stiffness is the effective stiffness of the plastic hinge region. The effective stiffness is proportional to the "EI" value of the section for the plastic hinge region. The ratio of the effective stiffness to the undamaged stiffness value is given in Table 2. It represents the first term in Eq. (4) (Priestley et al. 1996)

$$
\frac{k_{\mathrm{eff}}}{k_{0}}=\frac{1}{\mu}
$$

where $\mu=$ ductility level.

$k_{\text {eff }}$ is function of $E I$ and

$$
E I=\frac{M}{\phi}
$$

where $M=$ moment and $\phi=$ curvature. 


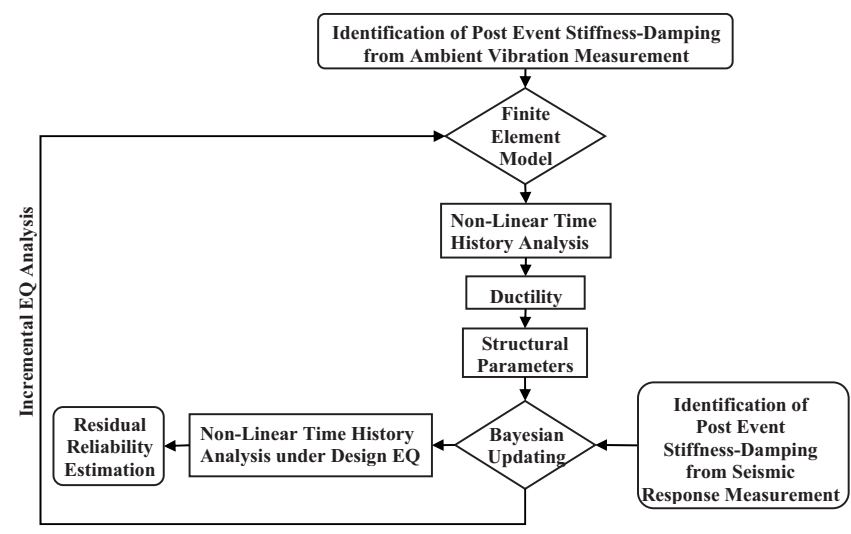

Fig. 6. Flowchart for the residual reliability estimation with updated parameters

In the plastic hinge region

$$
\phi=\frac{\theta}{L}
$$

where $\theta=$ rotation and $L=$ length of the plastic hinge region.

Therefore, identified effective stiffness value is inversely proportional to the rotational ductility. The mean of the stiffness value was calculated based on the 20 stiffness values. Eq. (7) was used to obtain the modal damping value at a specified damage based on the ductility level and the mean of the damping values (Kowalsky et al. 1994)

$$
\xi_{\text {eff }}=0.05+\frac{1}{\pi}\left(1-\frac{0.95}{\sqrt{\mu}}-\frac{0.05}{\sqrt{\mu}}\right)
$$

Monte Carlo simulation was performed again based on the mean values of the stiffness and damping coefficients considering they follow normal distribution. The second test, T-14 was used as the input for the nonlinear time history analysis and the same procedure was carried out for the other tests, T-15 and T-19. The stiffness and damping values generated at each damage level were also used in the nonlinear time history analyses under the design earthquake to determine structural response values in terms of rotational ductility. Design earthquake was chosen to be the last event, T-19 due to the fact that bridge structure experienced major damage under this input motion. Finding the remaining structural reliability which is $1-P_{f}$ under the given design earthquake then turns out to be straightforward.

\section{Reliability Estimation Based on Updated Structural Parameters}

Fig. 6 shows the flowchart to estimate the structural reliability using Bayesian updated structural parameter values based on the seismic response measurement. In this case, response values in terms of rotational ductility were obtained and considered to follow normal distribution as discussed previously; however this distribution was updated using the identified structural parameters based on the vibration measurement. The stiffness and the ductility values are inversely proportional to each other as discussed previously. New stiffness values and damping coefficients which are used for the following tests were determined based on this updated distribution. Structural reliability estimation was performed in the same way but using the updated distribution. It is emphasized that the preevent structural parameters, stiffness, and

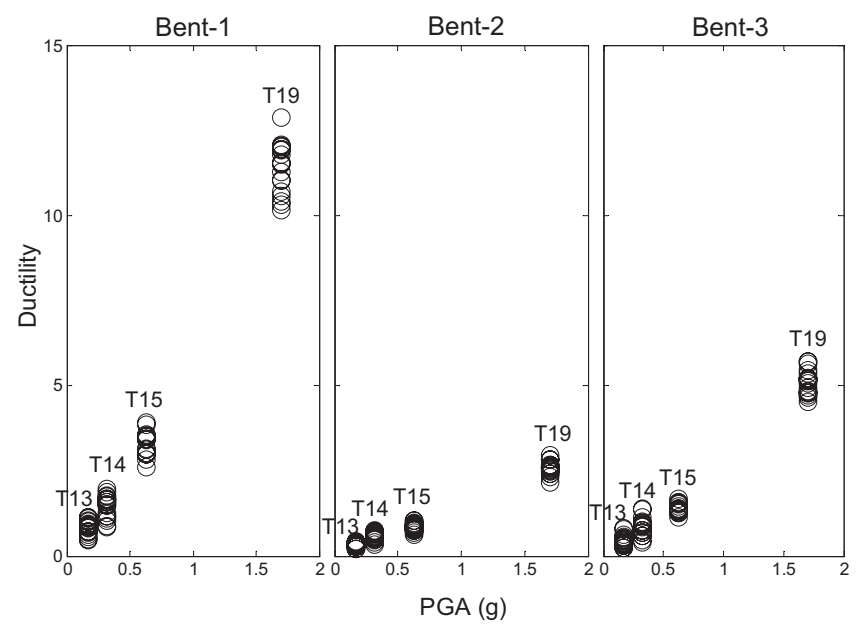

Fig. 7. Response values for nonupdated structural parameters

damping values are not the design values, but those identified from ambient vibration measurement. Similarly, the postevent structural parameters are not from the simulation, but identified from the seismic response measurement.

\section{Nonlinear Time History Analysis with Nonupdated Structural Parameters}

In this section structural response values obtained from nonlinear time history analyses using Monte Carlo simulated parameters, not the measured ones, are discussed. Fig. 7 shows the rotational ductility values under four different input motions. The PGA values are: $0.17,0.32,0.65$, and $1.70 \mathrm{~g}$. One can easily notice the similarities between this figure and the fragility curves obtained by many researchers for different purposes. The main difference as mentioned before is that the randomness in the response values is due to the randomness in the structural values but not due to the randomness in the input motion. Another observation is that Bent-1 suffers more damage than the other bents due to the torsional behavior in the response. In Fig. 7 and the following figures, only the rotational ductility values in the lower portion of each bent are presented, due to the fact that these values are higher than the ones obtained in the upper portions of the bents.

\section{Nonlinear Time History Analysis with Updated Structural Parameters}

In this section, structural response values obtained from nonlinear time history analyses using Bayesian updated were discussed. Fig. 8 shows an example hysteretic behavior of the bridge model under T-19 using Bayesian updated and nonupdated parameters. It shows that rotational ductility turns out to be larger if the structural values are updated using identification results in Bayesian sense. The logic behind nonlinear time history analyses was very similar to the one presented in the previous section; however in this case structural parameters were first updated in a Bayesian sense using the identification results. Therefore, Bayesian approach was summarized (Ang and Tang 1975). 


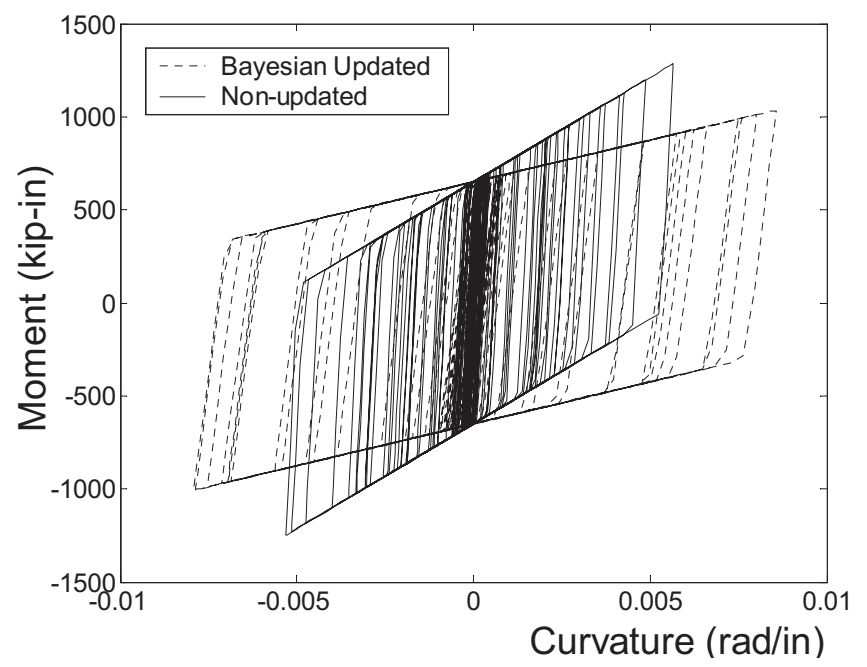

Fig. 8. Example responses under T-19

\section{Bayesian Approach}

Suppose that the possible values of a parameter $\theta$ were assumed to be a set of discrete values $\theta_{i}, i=1,2, \ldots, n$ with relative likelihoods $p_{i}=P\left(\Theta=\theta_{i}\right)(\Theta$ is the random variable whose values represent possible values of the parameter $\theta$ ). Then if additional information becomes available, in this case structural parameter identification, the prior assumptions on the parameter $\theta$ may be modified through Bayes' theorem as follows.

Let $\varepsilon$ denote observed outcome of the experiment. Then applying Bayes' theorem one can obtain

$$
P\left(\Theta=\theta_{i} \mid \varepsilon\right)=\frac{P\left(\varepsilon \mid \Theta=\theta_{i}\right) P\left(\Theta=\theta_{i}\right)}{\sum_{i=1}^{n} P\left(\varepsilon \mid \Theta=\theta_{i}\right) P\left(\Theta=\theta_{i}\right)} \quad i=1,2, \ldots, n
$$

$P\left(\varepsilon \mid \Theta=\theta_{i}\right)$ : the likelihood of the experimental outcome $\varepsilon$ if $\Theta$ $=\theta_{i}$; that is, the conditional probability of obtaining a particular experimental outcome assuming that the parameter is $\theta_{i}$. $P(\Theta$ $\left.=\theta_{i}\right)$ : the prior probability of $\Theta=\theta_{i}$; that is, prior to the availability of the experimental information $\varepsilon . P\left(\Theta=\theta_{i} \mid \varepsilon\right)$ : the posterior probability of $\Theta=\theta_{i}$; that is, the probability that has been revised in the light of the experimental outcome $\varepsilon$.

\section{Damage Assessment with and without Bayesian Updating}

Fig. 9 shows that prior distribution of the ductility values at the lower portion of Bent-1 is much lower than the condition distribution of the one during T-14. Prior distribution is for the ductility response values obtained by nonlinear time history analyses using Monte Carlo simulated structural parameters. Condition distribution is for the structural parameters directly identified based on

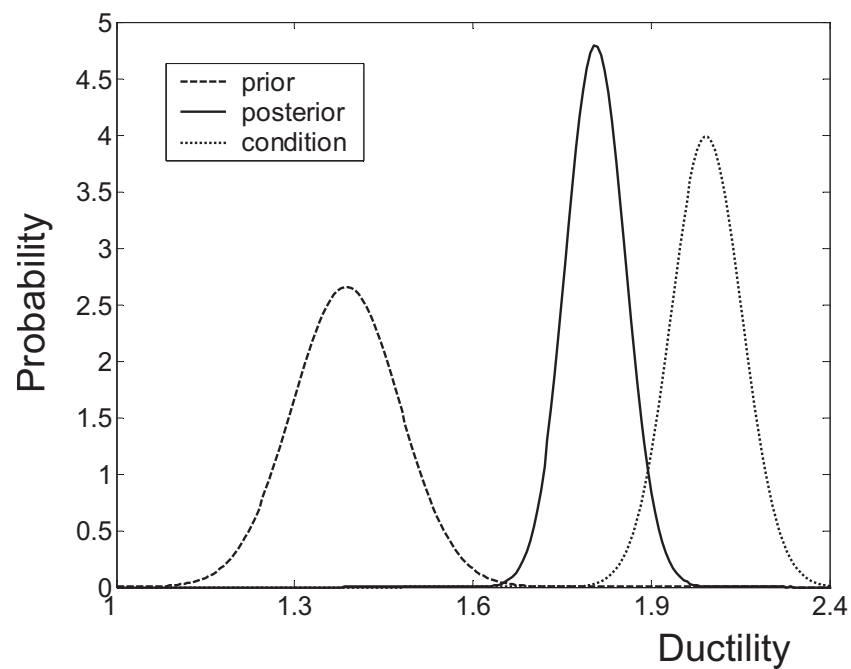

Fig. 9. Bayesian updating

seismic response measurement. As stated before, this prior distribution was updated in the Bayesian sense based on the condition distribution. The comparison was performed using prior and posterior distributions.

Table 3 presents the ductility values for nonupdated, updated, and conditional distributions for the T-13, T-14, and T15. Ductility values for the conditional distribution are the inverse stiffness values presented in Table 2 .

Fig. 10 shows the response values in terms of ductility computed from the updated and nonupdated structural values, i.e., prior and posterior distributions. The ductility values were bigger when Bayesian updated structural values are used. It implies that actually the structure experienced more damage than the one estimated based on nonupdated structural parameter values. Fig. 10 also shows that under T-19, Bent-3 experiences more damage than Bent-1 does, when the Bayesian updated structural parameter values are used. This is consistent with the experimental observation. However, if nonupdated structural parameters were used, Bent-1 experienced more damage than Bent-3 did. This demonstrates that integration of the vibration-based identification results not only results in more reliable estimation of the ductility but also the failure mode.

\section{Structural Reliability Estimation}

In this section, residual reliability estimation of the bridge structure was performed. In the previous section, two distributions for the structural parameters were obtained; namely updated and nonupdated distributions. In this section, these distributions were used for the nonlinear time history analyses under design earthquake. Fig. 11 shows the residual reliability of the bridge struc-

Table 3. Ductility Values for Nonupdated and Updated Parameters

\begin{tabular}{|c|c|c|c|c|c|c|c|c|c|}
\hline & \multicolumn{3}{|c|}{ T13 } & \multicolumn{3}{|c|}{ T14 } & \multicolumn{3}{|c|}{ T15 } \\
\hline & $\mathrm{NU}$ & $\mathrm{C}$ & $\mathrm{U}$ & $\mathrm{NU}$ & $\mathrm{C}$ & U & $\mathrm{NU}$ & $\mathrm{C}$ & U \\
\hline B1L & 0.84 & 1.28 & 0.98 & 1.39 & 2.08 & 1.81 & 3.12 & 4.68 & 3.88 \\
\hline B2L & 0.45 & 1.09 & 0.67 & 0.60 & 1.12 & 0.78 & 0.78 & 1.64 & 1.04 \\
\hline B3L & 0.56 & 1.25 & 0.83 & 0.86 & 1.56 & 0.98 & 1.42 & 3.35 & 2.11 \\
\hline
\end{tabular}

Note: $\mathrm{B}(1) \mathrm{L}=\mathrm{Bent}$ (1) lower portion; $\mathrm{NU}=$ nonupdated; $\mathrm{U}=$ updated; and $\mathrm{C}=$ condition. 


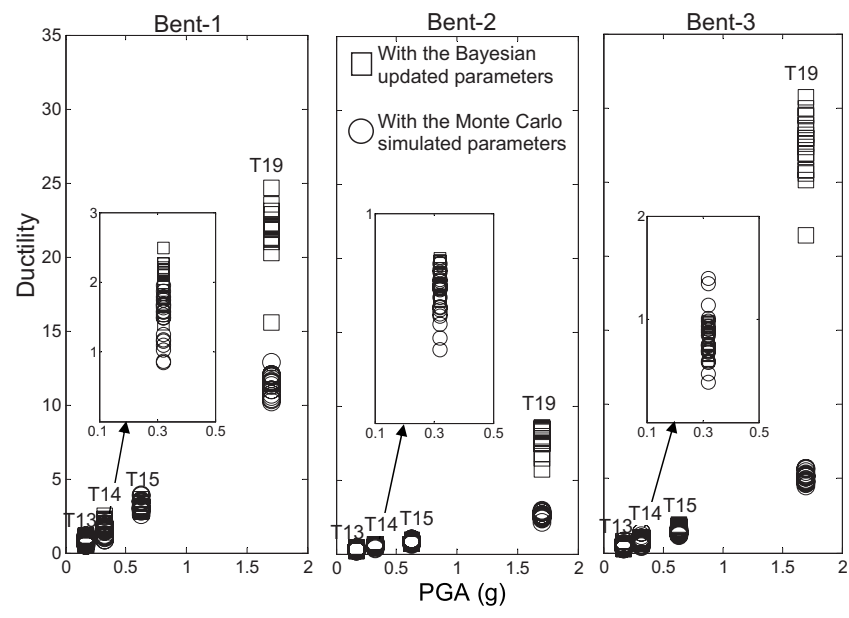

Fig. 10. Incremental response values for simulated structural values

ture under design earthquake after each damaging event. Design earthquake was chosen to be T-19 which had the input acceleration level sufficiently high to cause the structure to have major damage. The threshold level was determined based on Banerjee and Shinozuka (2008), in which they performed experimental observations and suggested different damage levels such as minor, moderate, major in terms of the ductility demand. In this research, the threshold rotational ductility was taken to be 9.42 , above which major damage was reported by Banerjee and Shinozuka (2008).

First, normal distribution is fit to the ductility response values after each event. Afterward, the structural reliability was determined as $1-P_{f}$. Table 4 clearly shows that in the scope of this example the remaining capacity is lower if the identification results from the measurement are incorporated. In other words, the estimation based on the nonupdated structural parameters will overestimate the reliability of the structure.

\section{Conclusions}

This paper presents the use of the structural parameter values identified based on vibration measurement and updated in Bayesian sense for the estimation of the reliability of a bridge structure

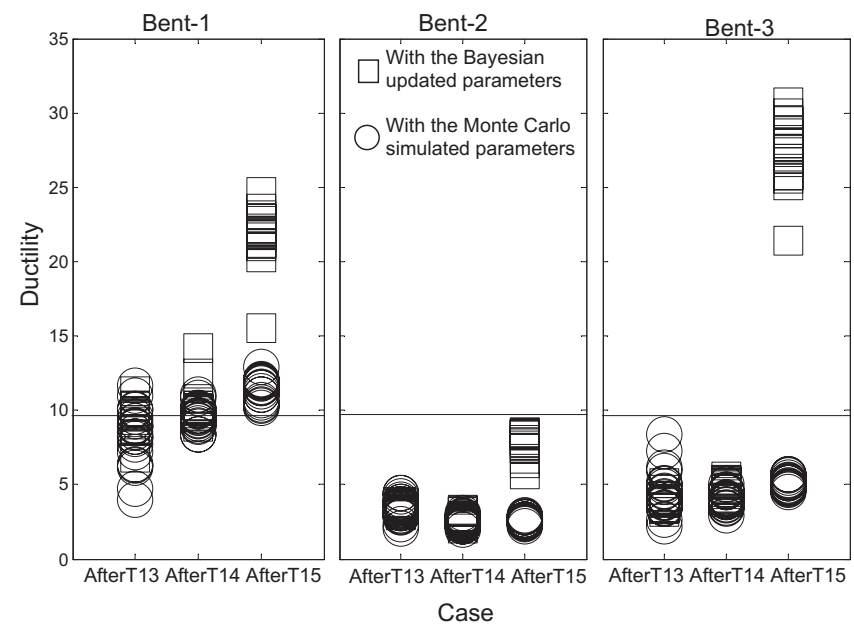

Fig. 11. Residual structural reliability estimation
Table 4. Residual Structural Reliability Values

\begin{tabular}{lccc}
\hline & After T13 & After T14 & After T15 \\
\hline Bayesian updated & $53 \%$ & $23 \%$ & $0 \%$ \\
Nonupdated & $75 \%$ & $44 \%$ & $3 \%$ \\
\hline
\end{tabular}

after a damaging event. In this study, a large-scale shaking table test of a three-bent concrete bridge model was performed in order to verify the proposed reliability estimation method. The bridge model was shaken to different damage levels by a sequence of earthquake motions with increasing intensities. The stiffness and damping values of the structure were instantaneously identified in real time during the damaging earthquake excitations, using the EKF approach previously developed by the writers. Based on the identified stiffness and damping values, residual structural reliability of the bridge was estimated. Following conclusions were made:

- In the scope of this paper, it was shown that structural reliability estimated using the Bayesian updated structural parameters was lower than the one estimated using nonupdated structural parameters mainly due to fact that the level of both stiffness and damping were considerably different after the updating procedure.

- Slight damage on Bent 1 was identified after T-13 based on vibration measurement. This level of damage is difficult to assess by visual inspection. Nonlinear time history analysis using the design values of the structural parameters could not simulate the stiffness degradation either.

- After T-14, damage could be inspected visually. The extent of the damage could be determined by nonlinear time history analysis, but it was always lower than the identification results based on vibration measurement.

These observations clearly reveal the importance of structural parameter identification both for postevent damage assessment and residual reliability estimation.

\section{Acknowledgments}

This study is sponsored by Caltrans, under the Research Grant No. 59A0311. The writers are thankful for insightful comments from project manager Mr. Li-Hong Sheng. The shaking table experiments were conducted at University of Nevada, Reno in conjunction with Dr. Saidii's and Sander's NSF-NEES project.

\section{References}

Ang, A. H.-S., and Tang, W. H. (1975). Probability concepts in engineering planning and design, Vol. I, Wiley, New York.

Banerjee, S., and Shinozuka, M. (2008). "Integration of empirical, analytical and experimental seismic damage data in the quantification of bridge seismic damage states." Proc., Concrete Bridge Conf. HPC-Safe, Affordable, and Efficient, Portland Cement Association, St. Louis, Mo.

Beck, J. L., and Katafygiotis, L. S. (1998). "Updating models and their uncertainties. I: Bayesian statistical framework." J. Eng. Mech., 124(4), 455-461.

Doebling, S. W., Farrar, C. R., Prime, M. B., and Shevitz, D. W. (1996). "Damage identification and health monitoring of structural and mechanical systems from changes in their vibration characteristics: A literature review." Los Alamos National Laboratory Rep. No. 
LA-13070-MS, The Regents of the Univ. of California and U.S. Government, Los Alamos, N.M.

Grewal, M. S., and Andrews, A. P. (2001). Kalman filtering theory and practice using Matlab, Wiley, New York.

Johnson, N. S., Saiidi, M., and Sanders, D. H. (2006). "Large-scale experimental and analytical seismic studies of a two-span reinforced concrete bridge system." Rep. No. CCEER-06-02, Center for Earthquake Engineering Research, Univ. of Nevada, Reno, Nev.

Katafygiotis, L. S., and Beck, J. L. (1998). "Updating models and their uncertainties. II: Model identifiability." J. Eng. Mech., 124(4), 463467.

Kowalsky, M. J., Priestley, M. J. N., and MacRae, G. A. (1994). "Displacement-based design. A methodology for seismic design applied to single degree of freedom reinforced concrete structures." Rep. No. SSRP 94/16, Univ. of California, San Diego.

Park, Y.-J., Ang, A. H.-S., and Wen, Y. K. (1985). "Seismic damage analysis of reinforced concrete buildings." J. Struct. Eng., 111(4), 740-757.
Priestley, M. J. N., Seible, F., and Calvi, G. M. (1996). Seismic design and retrofit of bridges, Wiley, New York.

Shinozuka, M., Feng, M. Q., Kim, H., Uzawa, T., and Ueda, T. (2003). "Statistical analysis of fragility curves." Technical Rep. No. MCEER03-002, Multidisciplinary Center for Earthquake Engineering Research, State Univ. of New York at Buffalo, New York.

Shinozuka, M., Feng, M. Q., Kim, H.-K., and Kim, S.-H. (2000a). "Nonlinear static procedure for fragility curve development." J. Eng. Mech., 126(12), 1287-1295.

Shinozuka, M., Feng, M. Q., Lee, J., and Naganuma, T. (2000b). "Statistical analysis of fragility curves." J. Eng. Mech., 126(12), 12241231.

Singhal, A., and Kiremidjian, A. S. (1998). "Bayesian updating of fragilities with application to RC frames." J. Struct. Eng., 124(8), 922-929.

Soyoz, S., and Feng, M. Q. (2008). "Seismic damage detection based on structural stiffness and experimental verification." Struct. Control Health Monit., 15(7), 958-973. 